\title{
Inquiry launched over AIDS contrarian's teaching
}

\section{Academic freedom should not be misused to spread theories that opponents say lack scientific evidence.}

\section{Zoë Corbyn}

\section{March 2012}

The University of Florence has launched an inquiry into the teaching activities of an academic who assisted on a course that denies the causal link between HIV and AIDS, and supervised students with dissertations on the same topic.

The Italian university's internal 'special commission' will examine the "teaching behaviour and responsibility" of molecular biologist Marco Ruggiero, a university spokesman told Nature.

The move follows a letter to the institution's rector, Alberto Tesi, by an Italian campaign group called the HIV Forum, which represents people infected with HIV and others concerned about the disease. It calls on him to disassociate the university from the "science and activities" of Ruggiero, who, the group says, is "internationally

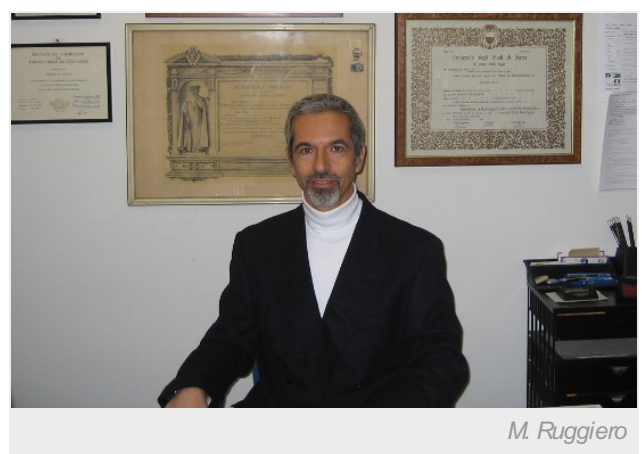

Marco Ruggiero does not believe that HIV causes AIDS. known" for denying the widely accepted link between HIV and AIDS, and promotes a potential cure for HIV involving an enriched probiotic yoghurt for which there is no proven evidence.

Tesi replied on 29 February to announce the special commission. This "will examine whether professor Ruggiero's conduct complies with the institutional guidelines on teaching contents and adherence to the objectives of the official curriculum of biological sciences", says university spokesman Duccio Di Bari, who adds that any misconduct would be dealt with internally. The commission comprises Elisabetta Cerbai, the university's vice-chancellor for research; Paola Bruni, the dean of the School of Science; Sergio Romagnani, an emeritus professor and expert in immunology; and Massimo Benedetti, who is responsible for university legal affairs. They will hold hearings behind closed doors.

\section{Death denial}

The investigation is the latest twist in the fallout from a paper ${ }^{1}$ published in December in the Italian Journal of Anatomy and Embryology (IJAE) by researchers including Peter Duesberg, an academic at the University of California, Berkeley, well know for denying the link between HIV and AIDS. The paper, which challenges estimates of HIV-AIDS death tolls in South Africa, has received heavy criticism from scientists, who have questioned how it could have passed peer review, and has led two members of the IJAE editorial board to resign in protest (see 'Paper denying HIV-AIDS link sparks resignation'). That Ruggiero was one of the paper's nine co-authors prompted the HIV Forum to write to the rector.

The forum cites two student dissertations mentored or co-mentored by Ruggiero that argue against the consensus that HIV causes AIDS 2,3 . "Most available evidence does not support a causative role for HIV in AIDS," they both conclude.

The HIV Forum also refers to a short elective course, consisting of two half days, which Nature understands ran twice in the 2010/11 academic year, and which Ruggiero collaborated on, entitled: 'The revolution of immunotherapy: prospects for the treatment of cancer and AIDS'. According to the description, the course teaches "the role of HIV in the pathogenesis of AIDS; association but not causation".

"What devastating effects can such false teaching have on future physicians and their patients?," asks the HIV Forum, stressing that although academic freedom is fundamental in teaching and research, it should not be misused to spread theories that they say are "lacking any scientific evidence".

"We hope the Commission will be scientifically rigorous and we hope that it will state that the best way to protect academic freedom is to teach according to the worldwide recognized scientific method," says a forum spokesperson.

\section{Parallel lines}


Ruggiero, whose supporters have also written to the rector, says he has always operated with scientific integrity and is confident he will be able to give any explanations that the committee asks for. He draws parallels with an inquiry the University of California held two years ago into the conduct of Duesberg, which resulted in no charges.

"Florence is famous for having been the city of Galileo Galilei, the worldwide recognized symbol of the predominance of scientific freedom over dogmas. I am convinced that freedom of teaching and research is a stronghold of our university system," he says. He adds that the student dissertations and the course were approved by the university.

The commission was welcomed by Fabio Marra, a professor of medicine at the university, who says the institution must shed "full light on the events".

"I believe that every researcher has the right to submit his or her work through peer-reviewed journals, no matter how little credibility that data may have," Marra says. "What is not acceptable is that personal theories, that are not supported by the weight of evidence, are taught to students that do not yet have the skills to form an independent opinion and to discriminate what they are being taught from what the bulk of the literature has shown."

The special commission is due to report by 15 April.

Nature I doi:10.1038/nature.2012.10250

\section{References}

1. Duesberg, P. H. et al. Ital. J. Anat. Embryol. 116, 73-92 (2011).

2. Branca, J. J. B. New Insights into the Role of HIV in the Aetiology and Pathogenesis of AIDS. Thesis, Univ. Florence http://wnw.marcoruggiero.org/pdf/HIV\%20and\%20AIDS\%20Thesis.pdf (2010).

3. Matteuzzi, C. Endogenous Retroviruses as Confounding Factors in the Pathogenesis of AIDS. Thesis, Univ. Florence http://aras.ab.ca/articles/scientific/20101021-Thesis-ChiaraMatteuzzi.pdf (2010). 